\title{
An Update on Safety and Side Effects of Cannabidiol: A Review of Clinical Data and Relevant Animal Studies
}

\author{
Kerstin Iffland and Franjo Grotenhermen
}

\begin{abstract}
Introduction: This literature survey aims to extend the comprehensive survey performed by Bergamaschi et al. in 2011 on cannabidiol (CBD) safety and side effects. Apart from updating the literature, this article focuses on clinical studies and CBD potential interactions with other drugs.

Results: In general, the often described favorable safety profile of CBD in humans was confirmed and extended by the reviewed research. The majority of studies were performed for treatment of epilepsy and psychotic disorders. Here, the most commonly reported side effects were tiredness, diarrhea, and changes of appetite/weight. In comparison with other drugs, used for the treatment of these medical conditions, CBD has a better side effect profile. This could improve patients' compliance and adherence to treatment. CBD is often used as adjunct therapy. Therefore, more clinical research is warranted on CBD action on hepatic enzymes, drug transporters, and interactions with other drugs and to see if this mainly leads to positive or negative effects, for example, reducing the needed clobazam doses in epilepsy and therefore clobazam's side effects.

Conclusion: This review also illustrates that some important toxicological parameters are yet to be studied, for example, if CBD has an effect on hormones. Additionally, more clinical trials with a greater number of participants and longer chronic CBD administration are still lacking.
\end{abstract}

Keywords: cannabidiol; cannabinoids; medical uses; safety; side effects; toxicity

\section{Introduction}

Since several years, other pharmacologically relevant constituents of the Cannabis plant, apart from $\Delta 9$ THC, have come into the focus of research and legislation. The most prominent of those is cannabidiol (CBD). In contrast to $\triangle 9$-THC, it is nonintoxicating, but exerts a number of beneficial pharmacological effects. For instance, it is anxiolytic, anti-inflammatory, antiemetic, and antipsychotic. Moreover, neuroprotective properties have been shown. ${ }^{1,2}$ Consequently, it could be used at high doses for the treatment of a variety of conditions ranging in psychiatric disorders such as schizophrenia and dementia, as well as diabetes and nausea. ${ }^{1,2}$
At lower doses, it has physiological effects that promote and maintain health, including antioxidative, anti-inflammatory, and neuroprotection effects. For instance, $\mathrm{CBD}$ is more effective than vitamin $\mathrm{C}$ and $\mathrm{E}$ as a neuroprotective antioxidant and can ameliorate skin conditions such as acne.,

The comprehensive review of 132 original studies by Bergamaschi et al. describes the safety profile of CBD, mentioning several properties: catalepsy is not induced and physiological parameters are not altered (heart rate, blood pressure, and body temperature). Moreover, psychological and psychomotor functions are not adversely affected. The same holds true for gastrointestinal transit, food intake, and absence of toxicity for

nova-Institut, Hürth, Germany.

*Address correspondence to: Kerstin Iffland, nova-Institut, Industriestraße 300, Hürth 50354, Germany, E-mail: kerstin.iffland@nova-institut.de

(c) Kerstin Iffland and Franjo Grotenhermen 2017; Published by Mary Ann Liebert, Inc. This is an Open Access article distributed under the terms of the Creative Commons Attribution License, which permits unrestricted use, distribution, and reproduction in any medium, provided the original work is properly cited. 
nontransformed cells. Chronic use and high doses of up to $1500 \mathrm{mg}$ per day have been repeatedly shown to be well tolerated by humans. ${ }^{1}$

Nonetheless, some side effects have been reported for $\mathrm{CBD}$, but mainly in vitro or in animal studies. They include alterations of cell viability, reduced fertilization capacity, and inhibition of hepatic drug metabolism and drug transporters (e.g., p-glycoprotein). ${ }^{1}$ Consequently, more human studies have to be conducted to see if these effects also occur in humans. In these studies, a large enough number of subjects have to be enrolled to analyze long-term safety aspects and CBD possible interactions with other substances.

This review will build on the clinical studies mentioned by Bergamaschi et al. and will update their survey with new studies published until September 2016.

\section{Relevant Preclinical Studies}

Before we discuss relevant animal research on CBD possible effects on various parameters, several important differences between route of administration and pharmacokinetics between human and animal studies have to be mentioned. First, CBD has been studied in humans using oral administration or inhalation. Administration in rodents often occures either via intraperitoneal injection or via the oral route. Second, the plasma levels reached via oral administration in rodents and humans can differ. Both these observations can lead to differing active blood concentrations of $\mathrm{CBD}^{1,5,6}$

In addition, it is possible that CBD targets differ between humans and animals. Therefore, the same blood concentration might still lead to different effects. Even if the targets, to which CBD binds, are the same in both studied animals and humans, for example, the affinity or duration of CBD binding to its targets might differ and consequently alter its effects.

The following study, which showed a positive effect of CBD on obsessive compulsive behavior in mice and reported no side effects, exemplifies the existing pharmacokinetic differences. ${ }^{5}$ When mice and humans are given the same CBD dose, more of the compound becomes available in the mouse organism. This higher bioavailability, in turn, can cause larger CBD effects.

Deiana et al. administered $120 \mathrm{mg} / \mathrm{kg}$ CBD either orally or intraperitoneally and measured peak plasma levels. ${ }^{5}$ The group of mice, which received oral CBD, had plasma levels of $2.2 \mu \mathrm{g} / \mathrm{ml} \mathrm{CBD}$. In contrast, i.p. injections resulted in peak plasma levels of $14.3 \mu \mathrm{g} / \mathrm{ml}$.
Administering $10 \mathrm{mg} / \mathrm{kg}$ oral $\mathrm{CBD}$ to humans leads to blood levels of $0.01 \mu \mathrm{g} / \mathrm{ml}{ }^{6}$ This corresponds to human blood levels of $0.12 \mu \mathrm{g} / \mathrm{ml}$, when $120 \mathrm{mg} / \mathrm{kg}$ $\mathrm{CBD}$ was given to humans. This calculation was performed assuming the pharmacokinetics of a hydrophilic compound, for simplicity's sake. We are aware that the actual levels of the lipophilic CBD will vary.

A second caveat of preclinical studies is that supraphysiological concentrations of compounds are often used. This means that the observed effects, for instance, are not caused by a specific binding of CBD to one of its receptors but are due to unspecific binding following the high compound concentration, which can inactivate the receptor or transporter.

The following example and calculations will demonstrate this. In vitro studies have shown that CBD inhibits the $\mathrm{ABC}$ transporters $\mathrm{P}$-gp ( $\mathrm{P}$ glycoprotein also referred to as ATP-binding cassette subfamily $\mathrm{B}$ member $1=A B C B 1 ; 3-100 \mu \mathrm{M} \quad \mathrm{CBD})$ and Bcrp (Breast Cancer Resistance Protein; also referred to as ABCG2 = ATP-binding cassette subfamily G member 2). ${ }^{7}$ After 3 days, the P-gp protein expression was altered in leukemia cells. This can have several implications because various anticancer drugs also bind to these membrane-bound, energy-dependent efflux transporters. ${ }^{1}$ The used CBD concentrations are supraphysiological, however, $3 \mu \mathrm{M}$ CBD approximately corresponds to plasma concentrations of $1 \mu \mathrm{g} / \mathrm{ml}$. On the contrary, a $700 \mathrm{mg}$ CBD oral dose reached a plasma level of $10 \mathrm{ng} / \mathrm{ml}^{6}{ }^{6}$ This means that to reach a $1 \mu \mathrm{g} / \mathrm{ml}$ plasma concentration, one would need to administer considerably higher doses of oral CBD. The highest ever applied CBD dose was $1500 \mathrm{mg}^{1}$. Consequently, more research is warranted, where the CBD effect on $\mathrm{ABC}$ transporters is analyzed using $\mathrm{CBD}$ concentrations of, for example, $0.03-0.06 \mu \mathrm{M}$. The rationale behind suggesting these concentrations is that studies summarized by Bih et al. on CBD effect on ABCC1 and ABCG2 in SF9 human cells showed that a CBD concentration of $0.08 \mu \mathrm{M}$ elicited the first effect. ${ }^{7}$

Using the pharmacokinetic relationships mentioned above, one would need to administer an oral CBD dose of $2100 \mathrm{mg}$ CBD to affect ABCC1 and ABCG2. We used $10 \mathrm{ng} / \mathrm{ml}$ for these calculations and the ones in Table $1,{ }^{6,8}$ based on a 6-week trial using a daily oral administration of $700 \mathrm{mg}$ CBD, leading to mean plasma levels of $6-11 \mathrm{ng} / \mathrm{ml}$, which reflects the most realistic scenario of CBD administration in patients. ${ }^{6}$ That these levels seem to be reproducible, and that chronic CBD administration does not lead to elevated mean 
Table 1. Inhibition of Human Metabolic Enzymes by Exogenous Cannabinoids In Vitro and the Extrapolated Levels of Oral Daily CBD Administration in Humans Needed to Reach These In Vitro Concentrations (Adapted)

\begin{tabular}{|c|c|c|c|c|c|c|c|c|c|c|}
\hline CYP-450 isoform & $1 \mathrm{~A} 1$ & $1 \mathrm{~A} 2$ & 1B1 & $2 A 6$ & $2 \mathrm{~B} 6$ & $2 C 9$ & 2D6 & $3 \mathrm{~A} 4$ & $3 A 5$ & $3 A 7$ \\
\hline $\begin{array}{l}\mathrm{CBD} \text { (in } \mu \mathrm{M}) \\
{ }^{\mathrm{a}} \text { Extrapolated oral daily CBD doses } \\
\text { to reach the levels above (in } \mathrm{mg} \text { ) }\end{array}$ & $\begin{array}{c}0.2 \\
4900\end{array}$ & $\begin{array}{c}2.7 \\
63,000\end{array}$ & $\begin{array}{c}3.6 \\
84,000\end{array}$ & $\begin{array}{c}55.0 \\
1.28 \text { Mio. }\end{array}$ & $\begin{array}{l}\quad 0.7 \\
\text { Ca. } 16,000\end{array}$ & $\begin{array}{c}0.9-9.9 \\
21,000-231,000\end{array}$ & $\begin{array}{c}1.2-2.7 \\
28,000-63,000\end{array}$ & $\begin{array}{c}1.0 \\
\text { Ca. } 23,000\end{array}$ & $\begin{array}{c}0.2 \\
4900\end{array}$ & $\begin{array}{c}12.3 \\
0.29 \text { Mio. }\end{array}$ \\
\hline
\end{tabular}

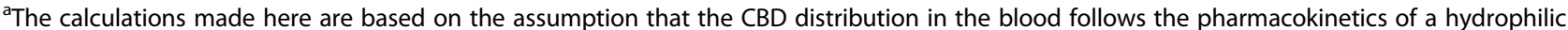
substance such as alcohol. The reality is more complex, because CBD is lipophilic and, for example, will consequently accumulate in fat tissue. These calculations were made with the intention to give the reader an impression and an approximation of the supraphysiological levels used in in vitro studies.

blood concentrations, was shown by another study. A single dose of $600 \mathrm{mg}$ led to reduced anxiety and mean CBD blood concentrations of $4.7-17 \mathrm{ng} / \mathrm{ml}^{9}{ }^{9}$

It also seems warranted to assume that the mean plasma concentration exerts the total of observed CBD effects, compared to using peak plasma levels, which only prevail for a short amount of time. This is not withstanding, that a recent study measured Cmax values for CBD of $221 \mathrm{ng} / \mathrm{ml}, 3 \mathrm{~h}$ after administration of $1 \mathrm{mg} / \mathrm{kg}$ fentanyl concomitantly with a single oral dose of $800 \mathrm{mg}$ CBD. ${ }^{10}$

\section{CBD-drug interactions}

Cytochrome P450-complex enzymes. This paragraph describes CBD interaction with general (drug)metabolizing enzymes, such as those belonging to the cytochrome P450 family. This might have an effect for coadministration of CBD with other drugs. ${ }^{7}$ For instance, $\mathrm{CBD}$ is metabolized, among others, via the CYP3A4 enzyme. Various drugs such as ketoconazol, itraconazol, ritonavir, and clarithromycin inhibit this enzyme. ${ }^{11}$ This leads to slower CBD degradation and can consequently lead to higher CBD doses that are longer pharmaceutically active. In contrast, phenobarbital, rifampicin, carbamazepine, and phenytoin induce CYP3A4, causing reduced CBD bioavailability. ${ }^{11}$ Approximately $60 \%$ of clinically prescribed drugs are metabolized via CYP3A4. ${ }^{1}$ Table 1 shows an overview of the cytochrome inhibiting potential of CBD. It has to be pointed out though, that the in vitro studies used supraphysiological CBD concentrations.

Studies in mice have shown that CBD inactivates cytochrome P450 isozymes in the short term, but can induce them after repeated administration. This is similar to their induction by phenobarbital, thereby implying the $2 \mathrm{~b}$ subfamily of isozymes. ${ }^{1}$ Another study showed this effect to be mediated by upregula- tion of mRNA for CYP3A, 2C, and 2B10, after repeated CBD administration. ${ }^{1}$

Hexobarbital is a CYP2C19 substrate, which is an enzyme that can be inhibited by CBD and can consequently increase hexobarbital availability in the organism. ${ }^{12,13}$ Studies also propose that this effect might be caused in vivo by one of CBD metabolites. ${ }^{14,15}$ Generally, the metabolite $6 \mathrm{a}-\mathrm{OH}-\mathrm{CBD}$ was already demonstrated to be an inducer of CYP2B10. Recorcinol was also found to be involved in CYP450 induction. The enzymes CYP3A and CYP2B10 were induced after prolonged CBD administration in mice livers, as well as for human CYP1A1 in vitro. ${ }^{14,15}$ On the contrary, CBD induces CYP1A1, which is responsible for degradation of cancerogenic substances such as benzopyrene. CYP1A1 can be found in the intestine and CBDinduced higher activity could therefore prevent absorption of cancerogenic substances into the bloodstream and thereby help to protect DNA. ${ }^{2}$

Effects on P-glycoprotein activity and other drug transporters. A recent study with P-gp, Bcrp, and $\mathrm{P}$-gp/Bcrp knockout mice, where $10 \mathrm{mg} / \mathrm{kg}$ was injected subcutaneously, showed that CBD is not a substrate of these transporters itself. This means that they do not reduce CBD transport to the brain. ${ }^{16}$ This phenomenon also occurs with paracetamol and haloperidol, which both inhibit P-gp, but are not actively transported substrates. The same goes for gefitinib inhibition of Bcrp.

These proteins are also expressed at the blood-brain barrier, where they can pump out drugs such as risperidone. This is hypothesized to be a cause of treatment resistance. ${ }^{16}$ In addition, polymorphisms in these genes, making transport more efficient, have been implied in interindividual differences in pharmacoresistance. ${ }^{10}$ Moreover, the CBD metabolite 7-COOH CBD might be a potent anticonvulsant itself. ${ }^{14}$ It will be interesting 
to see whether it is a P-gp substrate and alters pharmacokinetics of coadministered P-gp-substrate drugs.

An in vitro study using three types of trophoblast cell lines and ex vivo placenta, perfused with $15 \mu \mathrm{M} C B D$, found BCRP inhibition leading to accumulation of xenobiotics in the fetal compartment. ${ }^{17}$ BCRP is expressed at the apical side of the syncytiotrophoblast and removes a wide variety of compounds forming a part of the placental barrier. Seventy-two hours of chronic incubation with $25 \mu \mathrm{M}$ CBD also led to morphological changes in the cell lines, but not to a direct cytotoxic effect. In contrast, $1 \mu \mathrm{M}$ CBD did not affect cell and placenta viability. ${ }^{17}$ The authors consider this effect cytostatic. Nicardipine was used as the BCRP substrate in the in vitro studies, where the Jar cell line showed the largest increase in BCRP expression correlating with the highest level of transport. ${ }^{17 \text {,and references therein }}$

The ex vivo study used the antidiabetic drug and BCRP substrate glyburide. ${ }^{17}$ After $2 \mathrm{~h}$ of CBD perfusion, the largest difference between the CBD and the placebo placentas ( $n=8$ each) was observed. CBD inhibition of the BCRP efflux function in the placental cotyledon warrants further research of coadministration of CBD with known BCRP substrates such as nitrofurantoin, cimetidine, and sulfasalazine. In this study, a dose-response curve should be established in male and female subjects (CBD absorption was shown to be higher in women) because the concentrations used here are usually not reached by oral or inhaled CBD administration. Nonetheless, CBD could accumulate in organs physiologically restricted via a blood barrier. ${ }^{17}$

\section{Physiological effects}

CBD treatment of up to 14 days (3-30 $\mathrm{mg} / \mathrm{kg}$ b.w. i.p.) did not affect blood pressure, heart rate, body temperature, glucose levels, $\mathrm{pH}, \mathrm{pCO}_{2}, \mathrm{pO}_{2}$, hematocrit, $\mathrm{K}^{+}$or $\mathrm{Na}^{+}$levels, gastrointestinal transit, emesis, or rectal temperature in a study with rodents. ${ }^{1}$

Mice treated with $60 \mathrm{mg} / \mathrm{kg}$ b.w. CBD i.p. for 12 weeks (three times per week) did not show ataxia, kyphosis, generalized tremor, swaying gait, tail stiffness, changes in vocalization behavior or open-field physiological activity (urination, defecation). ${ }^{1}$

\section{Neurological and neurospychiatric effects}

Anxiety and depression. Some studies indicate that under certain circumstances, CBD acute anxiolytic effects in rats were reversed after repeated 14-day administration of CBD. ${ }^{2}$ However, this finding might depend on the used animal model of anxiety or depression.
This is supported by a study, where CBD was administered in an acute and "chronic" (2 weeks) regimen, which measured anxiolytic/antidepressant effects, using behavioral and operative models $(\mathrm{OBX}=$ olfactory bulbectomy as model for depression). ${ }^{18}$ The only observed side effects were reduced sucrose preference, reduced food consumption and body weight in the nonoperated animals treated with CBD $(50 \mathrm{mg} / \mathrm{kg})$. Nonetheless, the behavioral tests (for OBX-induced hyperactivity and anhedonia related to depression and open field test for anxiety) in the CBD-treated OBX animals showed an improved emotional response. Using microdialysis, the researchers could also show elevated 5-HT and glutamate levels in the prefrontal cortex of OBX animals only. This area was previously described to be involved in maladaptive behavioral regulation in depressed patients and is a feature of the OBX animal model of depression. The fact that serotonin levels were only elevated in the OBX mice is similar to CBD differential action under physiological and pathological conditions.

A similar effect was previously described in anxiety experiments, where CBD proved to be only anxiolytic in subjects where stress had been induced before CBD administration. Elevated glutamate levels have been proposed to be responsible for ketamine's fast antidepressant function and its dysregulation has been described in OBX mice and depressed patients. Chronic CBD treatment did not elicit behavioral changes in the nonoperated mice. In contrast, $\mathrm{CBD}$ was able to alleviate the affected functionality of $5 \mathrm{HT} 1 \mathrm{~A}$ receptors in limbic brain areas of OBX mice. ${ }^{18}$ and references therein

Schiavon et al. cite three studies that used chronic CBD administration to demonstrate its anxiolytic effects in chronically stressed rats, which were mostly mediated via hippocampal neurogenesis. ${ }^{19}$ and references therein For instance, animals received daily i.p. injections of $5 \mathrm{mg} / \mathrm{kg}$ CBD. Applying a $5 \mathrm{HT} 1 \mathrm{~A}$ receptor antagonist in the DPAG (dorsal periaqueductal gray area), it was implied that CBD exerts its antipanic effects via these serotonin receptors. No adverse effects were reported in this study.

Psychosis and bipolar disorder. Various studies on CBD and psychosis have been conducted. ${ }^{20}$ For instance, an animal model of psychosis can be created in mice by using the NMDAR antagonist MK-801. The behavioral changes (tested with the prepulse inhibition [PPI] test) were concomitant with decreased mRNA expression of the NMDAR GluN1 subunit 
gene (GRN1) in the hippocampus, decreased parvalbumin expression ( $=$ a calcium-binding protein expressed in a subclass of GABAergic interneurons), and higher FosB/ $\Delta$ FosB expression (=markers for neuronal activity). After 6 days of MK-801 treatment, various CBD doses were injected intraperitoneally $(15,30,60 \mathrm{mg} / \mathrm{kg})$ for 22 days. The two higher CBD doses had beneficial effects comparable to the atypical antipsychotic drug clozapine and also attenuated the MK-801 effects on the three markers mentioned above. The publication did not record any side effects. ${ }^{21}$

One of the theories trying to explain the etiology of bipolar disorder (BD) is that oxidative stress is crucial in its development. Valvassori et al. therefore used an animal model of amphetamine-induced hyperactivity to model one of the symptoms of mania. Rats were treated for 14 days with various CBD concentrations $(15,30,60 \mathrm{mg} / \mathrm{kg}$ daily i.p.). Whereas CBD did not have an effect on locomotion, it did increase brainderived neurotrophic factor (BDNF) levels and could protect against amphetamine-induced oxidative damage in proteins of the hippocampus and striatum. No adverse effects were recorded in this study. ${ }^{22}$

Another model for BD and schizophrenia is PPI of the startle reflex both in humans and animals, which is disrupted in these diseases. Peres et al., list five animal studies, where mostly $30 \mathrm{mg} / \mathrm{kg}$ CBD was administered and had a positive effect on PPI. ${ }^{20}$ Nonetheless, some inconsistencies in explaining $\mathrm{CBD}$ effects on PPI as model for BD exist. For example, CBD sometimes did not alter MK-801-induced PPI disruption, but disrupted PPI on its own. ${ }^{20}$ If this effect can be observed in future experiments, it could be considered to be a possible side effect.

Addiction. CBD, which is nonhedonic, can reduce heroin-seeking behavior after, for example, cueinduced reinstatement. This was shown in an animal heroin self-administration study, where mice received $5 \mathrm{mg} / \mathrm{kg}$ CBD i.p. injections. The observed effect lasted for 2 weeks after CBD administration and could normalize the changes seen after stimulus cue-induced heroin seeking (expression of AMPA, GluR1, and CB1R). In addition, the described study was able to replicate previous findings showing no CBD side effects on locomotor behavior. ${ }^{23}$

Neuroprotection and neurogenesis. There are various mechanisms underlying neuroprotection, for example, energy metabolism (whose alteration has been implied in several psychiatric disorders) and proper mitochondrial functioning. ${ }^{24}$ An early study from 1976 found no side effects and no effect of 0.3$300 \mu \mathrm{g} / \mathrm{mg}$ protein CBD after $1 \mathrm{~h}$ of incubation on mitochondrial monoamine oxidase activity in porcine brains. ${ }^{25}$ In hypoischemic newborn pigs, CBD elicited a neuroprotective effect, caused no side effects, and even led to beneficial effects on ventilatory, cardiac, and hemodynamic functions. ${ }^{26}$

A study comparing acute and chronic CBD administration in rats suggests an additional mechanism of CBD neuroprotection: Animals received i.p. CBD (15, $30,60 \mathrm{mg} / \mathrm{kg}$ b.w.) or vehicle daily, for 14 days. Mitochondrial activity was measured in the striatum, hippocampus, and the prefrontal cortex. ${ }^{27}$ Acute and chronic $\mathrm{CBD}$ injections led to increased mitochondrial activity (complexes I-V) and creatine kinase, whereas no side effects were documented. Chronic CBD treatment and the higher $\mathrm{CBD}$ doses tended to affect more brain regions. The authors hypothesized that $\mathrm{CBD}$ changed the intracellular $\mathrm{Ca}^{2+}$ flux to cause these effects. Since the mitochondrial complexes I and II have been implied in various neurodegenerative diseases and also altered ROS (reactive oxygen species) levels, which have also been shown to be altered by CBD, this might be an additional mechanism of CBD-mediated neuroprotection., ${ }^{1,27}$

Interestingly, it has recently been shown that the higher ROS levels observed after CBD treatment were concomitant with higher mRNA and protein levels of heat shock proteins (HSPs). In healthy cells, this can be interpreted as a way to protect against the higher ROS levels resulting from more mitochondrial activity. In addition, it was shown that HSP inhibitors increase the CBD anticancer effect in vitro. ${ }^{28}$ This is in line with the studies described by Bergamaschi et al., which also imply ROS in CBD effect on (cancer) cell viability in addition to, for example, proapoptotic pathways such as via caspase-8/9 and inhibition of the procarcinogenic lipoxygenase pathway. ${ }^{1}$

Another publication studied the difference of acute and chronic administration of two doses of CBD in nonstressed mice on anxiety. Already an acute i.p. administration of $3 \mathrm{mg} / \mathrm{kg}$ was anxiolytic to a degree comparable to $20 \mathrm{mg} / \mathrm{kg}$ imipramine (an selective serotonin reuptake inhibitor [SSRI] commonly prescribed for anxiety and depression). Fifteen days of repeated i.p. administration of $3 \mathrm{mg} / \mathrm{kg}$ CBD also increased cell proliferation and neurogenesis (using three different markers) in the subventricular zone and the hippocampal dentate gyrus. 
Interestingly, the repeated administration of $30 \mathrm{mg} / \mathrm{kg}$ also led to anxiolytic effects. However, the higher dose caused a decrease in neurogenesis and cell proliferation, indicating dissociation of behavioral and proliferative effects of chronic CBD treatment. The study does not mention adverse effects. ${ }^{19}$

\section{Immune system}

Numerous studies show the CBD immunomodulatory role in various diseases such as multiple sclerosis, arthritis, and diabetes. These animal and human ex vivo studies have been reviewed extensively elsewhere, but studies with pure CBD are still lacking. Often combinations of THC and CBD were used. It would be especially interesting to study when CBD is proinflammatory and under which circumstances it is anti-inflammatory and whether this leads to side effects (Burstein, 2015: Table 1 shows a summary of its anti-inflammatory actions; McAllister et al. give an extensive overview in Table 1 of the interplay between CBD anticancer effects and inflammation signaling). ${ }^{29,30}$

In case of Alzheimer's disease (AD), studies in mice and rats showed reduced amyloid beta neuroinflammation (linked to reduced interleukin [IL]-6 and microglial activation) after CBD treatment. This led to amelioration of learning effects in a pharmacological model of $\mathrm{AD}$. The chronic study we want to describe in more detail here used a transgenic mouse model of $\mathrm{AD}$, where 2.5 -month-old mice were treated with either placebo or daily oral CBD doses of $20 \mathrm{mg} / \mathrm{kg}$ for 8 months (mice are relatively old at this point). CBD was able to prevent the development of a social recognition deficit in the $\mathrm{AD}$ transgenic mice.

Moreover, the elevated IL-1 beta and TNF alpha levels observed in the transgenic mice could be reduced to WT (wild-type) levels with CBD treatment. Using statistical analysis by analysis of variance, this was shown to be only a trend. This might have been caused by the high variation in the transgenic mouse group, though. Also, CBD increased cholesterol levels in WT mice but not in CBD-treated transgenic mice. This was probably due to already elevated cholesterol in the transgenic mice. The study observed no side effects. ${ }^{31}$ and references within

In nonobese diabetes-prone female mice (NOD), CBD was administered i.p. for 4 weeks (5 days a week) at a dose of $5 \mathrm{mg} / \mathrm{kg}$ per day. After CBD treatment was stopped, observation continued until the mice were 24 weeks old. CBD treatment lead to considerable reduction of diabetes development (32\% devel- oped glucosuria in the CBD group compared to $100 \%$ in untreated controls) and to more intact islet of Langerhans cells. CBD increased IL-10 levels, which is thought to act as an anti-inflammatory cytokine in this context. The IL-12 production of splenocytes was reduced in the CBD group and no side effects were recorded. ${ }^{32}$

After inducing arthritis in rats using Freund's adjuvant, various CBD doses $(0.6,3.1,6.2$, or $62.3 \mathrm{mg} /$ day) were applied daily in a gel for transdermal administration for 4 days. CBD reduced joint swelling, immune cell infiltration. thickening of the synovial membrane, and nociceptive sensitization/spontaneous pain in a dose-dependent manner, after four consecutive days of CBD treatment. Proinflammatory biomarkers were also reduced in a dose-dependent manner in the dorsal root ganglia (TNF alpha) and spinal cord (CGRP, OX42). No side effects were evident and exploratory behavior was not altered (in contrast to $\triangle 9$-THC, which caused hypolocomotion). ${ }^{33}$

\section{Cell migration}

Embryogenesis. CBD was shown to be able to influence migratory behavior in cancer, which is also an important aspect of embryogenesis. ${ }^{1}$ For instance, it was recently shown that $\mathrm{CBD}$ inhibits Id-1. Helix-loophelix Id proteins play a role in embryogenesis and normal development via regulation of cell differentiation. High Id1-levels were also found in breast, prostate, brain, and head and neck tumor cells, which were highly aggressive. In contrast, Id1 expression was low in noninvasive tumor cells. Id 1 seems to influence the tumor cell phenotype by regulation of invasion, epithelial to mesenchymal transition, angiogenesis, and cell proliferation. ${ }^{34}$

There only seems to exist one study that could not show an adverse CBD effect on embryogenesis. An in vitro study could show that the development of two-cell embryos was not arrested at CBD concentrations of $6.4,32$, and $160 \mathrm{nM}^{35}$

Cancer. Various studies have been performed to study CBD anticancer effects. CBD anti-invasive actions seem to be mediated by its TRPV1 stimulation and its action on the $\mathrm{CB}$ receptors. Intraperitoneal application of $5 \mathrm{mg} / \mathrm{kg}$ b.w. CBD every 3 days for a total of 28 weeks, almost completely reduced the development of metastatic nodules caused by injection of human lung carcinoma cells (A549) in nude mice. ${ }^{36}$ This effect was mediated by upregulation of ICAM1 and TIMP1. 
This, in turn, was caused by upstream regulation of $\mathrm{p} 38$ and p42/44 MAPK pathways. The typical side effects of traditional anticancer medication, emesis, and collateral toxicity were not described in these studies. Consequently, CBD could be an alternative to other MMP1 inhibitors such as marimastat and prinomastat, which have shown disappointing clinical results due to these drugs' adverse muscoskeletal effects. ${ }^{37,38}$

Two studies showed in various cell lines and in tumor-bearing mice that $\mathrm{CBD}$ was able to reduce tumor metastasis. ${ }^{34,39}$ Unfortunately, the in vivo study was only described in a conference abstract and no route of administration or CBD doses were mentioned. ${ }^{36}$ However, an earlier study used $0.1,1.0$, or $1.5 \mu \mathrm{mol} / \mathrm{L}$ CBD for 3 days in the aggressive breast cancer cells MDA-MB231. CBD downregulated Id1 at promoter level and reduced tumor aggressiveness. ${ }^{40}$

Another study used xenografts to study the proapoptotic effect of CBD, this time in LNCaP prostate carcinoma cells. ${ }^{36}$ In this 5-week study, $100 \mathrm{mg} / \mathrm{kg}$ CBD was administered daily i.p. Tumor volume was reduced by $60 \%$ and no adverse effects of treatment were described in the study. The authors assumed that the observed antitumor effects were mediated via TRPM8 together with ROS release and p53 activation. ${ }^{41}$ It has to be pointed out though, that xenograft studies only have limited predictive validity to results with humans. Moreover, to carry out these experiments, animals are often immunologically compromised, to avoid immunogenic reactions as a result to implantation of human cells into the animals, which in turn can also affect the results. ${ }^{42}$

Another approach was chosen by Aviello et al. ${ }^{43}$ They used the carcinogen azoxymethane to induce colon cancer in mice. Treatment occurred using IP injections of 1 or $5 \mathrm{mg} / \mathrm{kg} \mathrm{CBD}$, three times a week for 3 weeks (including 1 week before carcinogen administration). After 3 months, the number of aberrant crypt foci, polyps, and tumors was analyzed. The high CBD concentration led to a significant decrease in polyps and a return to near-normal levels of phosphorylated Akt (elevation caused by the carcinogen). ${ }^{42}$ No adverse effects were mentioned in the described study. ${ }^{43}$

\section{Food intake and glycemic effects}

Animal studies summarized by Bergamaschi et al. showed inconclusive effects of CBD on food intake ${ }^{1}$ : i.p. administration of $3-100 \mathrm{mg} / \mathrm{kg}$ b.w. had no effect on food intake in mice and rats. On the contrary, the induction of hyperphagia by $\mathrm{CB} 1$ and 5HT1A agonists in rats could be decreased with CBD $(20 \mathrm{mg} / \mathrm{kg}$ b.w. i.p.). Chronic administration (14 days, 2.5 or $5 \mathrm{mg} /$ $\mathrm{kg}$ i.p.) reduced the weight gain in rats. This effect could be inhibited by coadministration of a CB2R antagonist. ${ }^{1}$

The positive effects of CBD on hyperglycemia seem to be mainly mediated via $\mathrm{CBD}$ anti-inflammatory and antioxidant effects. For instance, in ob/ob mice (an animal model of obesity), 4-week treatment with $3 \mathrm{mg} / \mathrm{kg}$ (route of administration was not mentioned) increased the HDL-C concentration by $55 \%$ and reduced total cholesterol levels by more than $25 \%$. In addition, treatment increased adiponectin and liver glycogen concentrations. ${ }^{44}$ and references therein

\section{Endocrine effects}

High CBD concentrations ( $1 \mathrm{mM})$ inhibited progesterone 17-hydroxylase, which creates precursors for sex steroid and glucocorticoid synthesis, whereas $100 \mu \mathrm{M}$ CBD did not in an in vitro experiment with primary testis microsomes. ${ }^{45}$ Rats treated with $10 \mathrm{mg} / \mathrm{kg}$ i.p. b.w. CBD showed inhibition of testosterone oxidation in the liver. ${ }^{46}$

\section{Genotoxicity and mutagenicity}

Jones et al. mention that $120 \mathrm{mg} / \mathrm{kg}$ CBD delivered intraperetonially to Wistar Kyoto rats showed no mutagenicity and genotoxicity based on personal communication with GW Pharmaceuticals ${ }^{47,48}$ These data are yet to be published. The 2012 study with an epilepsy mouse model could also show that CBD did not influence grip strength, which the study describes as a "putative test for functional neurotoxicity." 48

Motor function was also tested on a rotarod, which was also not affected by CBD administration. Static beam performance, as an indicator of sensorimotor coordination, showed more footslips in the CBD group, but CBD treatment did not interfere with the animals' speed and ability to complete the test. Compared to other anticonvulsant drugs, this effect was minimal. ${ }^{48}$ Unfortunately, we could not find more studies solely focusing on genotoxicity by other research groups neither in animals nor in humans.

\section{Acute Clinical Data}

Bergamaschi et al. list an impressive number of acute and chronic studies in humans, showing CBD safety for a wide array of side effects. ${ }^{1}$ They also conclude from their survey, that none of the studies reported 
tolerance to CBD. Already in the 1970s, it was shown that oral CBD (15-160 mg), iv injection (5-30 mg), and inhalation of $0.15 \mathrm{mg} / \mathrm{kg}$ b.w. CBD did not lead to adverse effects. In addition, psychomotor function and psychological functions were not disturbed. Treatment with up to $600 \mathrm{mg}$ CBD neither influenced physiological parameters (blood pressure, heart rate) nor performance on a verbal paired-associate learning test. ${ }^{1}$

Fasinu et al. created a table with an overview of clinical studies currently underway, registered in Clinical Trials. gov. ${ }^{49}$ In the following chapter, we highlight recent, acute clinical studies with CBD.

\section{CBD-drug interactions}

CBD can inhibit CYP2D6, which is also targeted by omeprazole and risperidone. ${ }^{2,14}$ There are also indications that $\mathrm{CBD}$ inhibits the hepatic enzyme CYP2C9, reducing the metabolization of warfarin and diclofenac. ${ }^{2,14}$ More clinical studies are needed, to check whether this interaction warrants an adaption of the used doses of the coadministered drugs.

The antibiotic rifampicin induces CYP3A4, leading to reduced $\mathrm{CBD}$ peak plasma concentrations. ${ }^{14}$ In contrast, the CYP3A4 inhibitor ketoconazole, an antifungal drug, almost doubles $\mathrm{CBD}$ peak plasma concentration. Interestingly, the CYP2C19 inhibitor omeprazole, used to treat gastroesophageal reflux, could not significantly affect the pharmacokinetics of CBD. ${ }^{14}$

A study, where a regimen of $6 \times 100 \mathrm{mg}$ CBD daily was coadministered with hexobarbital in 10 subjects, found that CBD increased the bioavailability and elimination half-time of the latter. Unfortunately, it was not mentioned whether this effect was mediated via the cytochrome P450 complex. ${ }^{16}$

Another aspect, which has not been thoroughly looked at, to our knowledge, is that several cytochrome isozymes are not only expressed in the liver but also in the brain. It might be interesting to research organspecific differences in the level of CBD inhibition of various isozymes. Apart from altering the bioavailability in the overall plasma of the patient, this interaction might alter therapeutic outcomes on another level. Dopamine and tyramine are metabolized by CYP2D6, and neurosteroid metabolism also occurs via the isozymes of the CYP3A subgroup. ${ }^{50,51}$ Studying CBD interaction with neurovascular cytochrome P450 enzymes might also offer new mechanisms of action. It could be possible that CBD-mediated CYP2D6 inhibition increases dopamine levels in the brain, which could help to explain the positive CBD effects in addiction/withdrawal scenarios and might support its 5HT (=serotonin) elevating effect in depression.

Also, CBD can be a substrate of UDP glucuronosyltransferase. ${ }^{14}$ Whether this enzyme is indeed involved in the glucuronidation of CBD and also causes clinically relevant drug interactions in humans is yet to be determined in clinical studies. Generally, more human studies, which monitor CBD-drug interactions, are needed.

\section{Physiological effects}

In a double-blind, placebo-controlled crossover study, CBD was coadministered with intravenous fentanyl to a total of 17 subjects. ${ }^{10}$ Blood samples were obtained before and after $400 \mathrm{mg}$ CBD (previously demonstrated to decrease blood flow to (para)limbic areas related to drug craving) or $800 \mathrm{mg}$ CBD pretreatment. This was followed by a single 0.5 (Session 1) or $1.0 \mu \mathrm{g} / \mathrm{kg}$ (Session 2, after 1 week of first administration to allow for sufficient drug washout) intravenous fentanyl dose. Adverse effects and safety were evaluated with both forms of the Systematic Assessment for Treatment Emergent Events (SAFTEE). This extensive tool tests, for example, 78 adverse effects divided into 23 categories corresponding to organ systems or body parts. The SAFTEE outcomes were similar between groups. No respiratory depression or cardiovascular complications were recorded during any test session.

The results of the evaluation of pharmacokinetics, to see if interaction between the drugs occurred, were as follows. Peak CBD plasma concentrations of the 400 and $800 \mathrm{mg}$ group were measured after $4 \mathrm{~h}$ in the first session (CBD administration $2 \mathrm{~h}$ after light breakfast). Peak urinary $\mathrm{CBD}$ and its metabolite concentrations occurred after $6 \mathrm{~h}$ in the low CBD group and after $4 \mathrm{~h}$ in the high CBD group. No effect was evident for urinary $\mathrm{CBD}$ and metabolite excretion except at the higher fentanyl dose, in which CBD clearance was reduced. Importantly, fentanyl coadministration did not produce respiratory depression or cardiovascular complications during the test sessions and CBD did not potentiate fentanyl's effects. No correlation was found between CBD dose and plasma cortisol levels.

Various vital signs were also measured (blood pressure, respiratory/heart rate, oxygen saturation, EKG, respiratory function): CBD did not worsen the adverse effects (e.g., cardiovascular compromise, respiratory depression) of iv fentanyl. Coadministration was safe and well tolerated, paving the way to use $\mathrm{CBD}$ as a 
potential treatment for opioid addiction. The validated subjective measures scales Anxiety (visual analog scale [VAS]), PANAS (positive and negative subscores), and OVAS (specific opiate VAS) were administered across eight time points for each session without any significant main effects for CBD for any of the subjective effects on mood. ${ }^{10}$

A Dutch study compared subjective adverse effects of three different strains of medicinal cannabis, distributed via pharmacies, using VAS. "Visual analog scale is one of the most frequently used psychometric instruments to measure the extent and nature of subjective effects and adverse effects. The 12 adjectives used for this study were as follows: alertness, tranquility, confidence, dejection, dizziness, confusion/disorientation, fatigue, anxiety, irritability, appetite, creative stimulation, and sociability." The high CBD strain contained the following concentrations: $6 \% \Delta 9$ THC/7.5\% CBD $(n=25)$. This strain showed significantly lower levels of anxiety and dejection. Moreover, appetite increased less in the high CBD strain. The biggest observed adverse effect was "fatigue" with a score of 7 (out of 10), which did not differ between the three strains. ${ }^{52}$

\section{Neurological and neurospychiatric effects}

Anxiety. Forty-eight participants received subanxiolytic levels (32 mg) of CBD, either before or after the extinction phase in a double-blind, placebo-controlled design of a Pavlovian fear-conditioning experiment (recall with conditioned stimulus and context after $48 \mathrm{~h}$ and exposure to unconditioned stimulus after reinstatement). Skin conductance (=autonomic response to conditioning) and shock expectancy measures (=explicit aspects) of conditioned responding were recorded throughout. Among other scales, the Mood Rating Scale (MRS) and the Bond and Bodily Symptoms Scale were used to assess anxiety, current mood, and physical symptoms. "CBD given postextinction (active after consolidation phase) enhanced consolidation of extinction learning as assessed by shock expectancy." Apart from the extinction-enhancing effects of CBD in human aversive conditioned memory, CBD showed a trend toward some protection against reinstatement of contextual memory. No side/adverse effects were reported. $^{53}$

Psychosis. The review by Bergamaschi et al. mentions three acute human studies that have demonstrated the CBD antipsychotic effect without any adverse effects being observed. This holds especially true for the extrapyramidal motor side effects elicited by classical antipsychotic medication. ${ }^{1}$

Fifteen male, healthy subjects with minimal prior $\Delta 9$-THC exposure ( $<15$ times) were tested for CBD affecting $\triangle 9$-THC propsychotic effects using functional magnetic resonance imaging (fMRI) and various questionnaires on three occasions, at 1-month intervals, following administration of $10 \mathrm{mg}$ delta-9- $\Delta 9$-THC, $600 \mathrm{mg}$ CBD, or placebo. Order of drug administration was pseudorandomized across subjects, so that an equal number of subjects received any of the drugs during the first, second, or third session in a double-blind, repeated-measures, within-subject design. ${ }^{54}$ No CBD effect on psychotic symptoms as measured with PANSS positive symptoms subscale, anxiety as indexed by the State Trait Anxiety Inventory (STAI) state, and Visual Analogue Mood Scale (VAMS) tranquilization or calming subscale, compared to the placebo group, was observed. The same is true for a verbal learning task (=behavioral performance of the verbal memory).

Moreover, pretreatment with $\mathrm{CBD}$ and subsequent $\triangle 9$-THC administration could reduce the latter's psychotic and anxiety symptoms, as measured using a standardized scale. This effect was caused by opposite neural activation of relevant brain areas. In addition, no effects on peripheral cardiovascular measures such as heart rate and blood pressure were measured. ${ }^{54}$

A randomized, double-blind, crossover, placebocontrolled trial was conducted in 16 healthy nonanxious subjects using a within-subject design. Oral $\Delta 9-\mathrm{THC}=10 \mathrm{mg}, \mathrm{CBD}=600 \mathrm{mg}$, or placebo was administered in three consecutive sessions at 1-month intervals. The doses were selected to only evoke neurocognitive effects without causing severe toxic, physical, or psychiatric reactions. The $600 \mathrm{mg}$ CBD corresponded to mean (standard deviation) whole blood levels of $0.36(0.64), 1.62(2.98)$, and $3.4(6.42) \mathrm{ng} / \mathrm{mL}, 1,2$, and $3 \mathrm{~h}$ after administration, respectively.

Physiological measures and symptomatic effects were assessed before, and at 1,2 , and $3 \mathrm{~h}$ postdrug administration using PANSS (a 30-item rating instrument used to assess psychotic symptoms, with ratings based on a semistructured clinical interview yielding subscores for positive, negative, and general psychopathology domains), the self-administered VAMS with 16 items (e.g., mental sedation or intellectual impairment, physical sedation or bodily impairments, anxiety effects and other types of feelings or attitudes), the ARCI (Addiction Research Center Inventory; containing empirically 
derived drug-induced euphoria; stimulant-like effects; intellectual efficiency and energy; sedation; dysphoria; and somatic effects) to assess drug effects and the STAI-T/S, where subjects were evaluated on their current mood and their feelings in general.

There were no significant differences between the effects of CBD and placebo on positive and negative psychotic symptoms, general psychopathology (PANSS), anxiety (STAI-S), dysphoria (ARCI), sedation (VAMS, ARCI), and the level of subjective intoxication (ASI, ARCI), where $\triangle 9$-THC did have a pronounced effect. The physiological parameters, heart rate and blood pressure, were also monitored and no significant difference between the placebo and the CBD group was observed. ${ }^{55}$

Addiction. A case study describes a patient treated for cannabis withdrawal according to the following CBD regimen: "treated with oral $300 \mathrm{mg}$ on Day 1; CBD $600 \mathrm{mg}$ on Days 2-10 (divided into two doses of $300 \mathrm{mg}$ ), and CBD $300 \mathrm{mg}$ on Day 11." CBD treatment resulted in a fast and progressive reduction in withdrawal, dissociative and anxiety symptoms, as measured with the Withdrawal Discomfort Score, the Marijuana Withdrawal Symptom Checklist, Beck Anxiety Inventory, and Beck Depression Inventory (BDI). Hepatic enzymes were also measured daily, but no effect was reported. ${ }^{56}$

Naturalistic studies with smokers inhaling cannabis with varying amounts of $\mathrm{CBD}$ showed that the $\mathrm{CBD}$ levels were not altering psychomimetic symptoms. ${ }^{1}$ Interestingly, $\mathrm{CBD}$ was able to reduce the "wanting/ liking" = implicit attentional bias caused by exposure to cannabis and food-related stimuli. CBD might work to alleviate disorders of addiction, by altering the attentive salience of drug cues. The study did not further measure side effects. ${ }^{57}$

$\mathrm{CBD}$ can also reduce heroin-seeking behaviors (e.g., induced by a conditioned cue). This was shown in the preclinical data mentioned earlier and was also replicated in a small double-blind pilot study with individuals addicted to opioids, who have been abstinent for 7 days. ${ }^{52,53}$ They either received placebo or 400 or $800 \mathrm{mg}$ oral CBD on three consecutive days. Craving was induced with a cue-induced reinstatement paradigm ( $1 \mathrm{~h}$ after CBD administration). One hour after the video session, subjective craving was already reduced after a single CBD administration. The effect persisted for 7 days after the last CBD treatment. Interestingly, anxiety measures were also reduced after treatment, whereas no adverse effects were described. ${ }^{23,58}$
A pilot study with 24 subjects was conducted in a randomized, double-blind, placebo-controlled design to evaluate the impact of the ad hoc use of CBD in smokers, who wished to stop smoking. Pre- and post-testing for mood and craving of the participants was executed. These tests included the Behaviour Impulsivity Scale, BDI, STAI, and the Severity of Dependence Scale. During the week of CBD inhalator use, subjects used a diary to log their craving (on a scale from 1 to $100=$ VAS measuring momentary subjective craving), the cigarettes smoked, and the number of times they used the inhaler. Craving was assessed using the Tiffany Craving Questionnaire (11). On day 1 and 7, exhaled $\mathrm{CO}$ was measured to test smoking status. Sedation, depression, and anxiety were evaluated with the MRS.

Over the course of 1 week, participants used the inhaler when they felt the urge to smoke and received a dose of $400 \mu \mathrm{g} \mathrm{CBD}$ via the inhaler (leading to $>65 \%$ bioavailability); this significantly reduced the number of cigarettes smoked by ca. $40 \%$, while craving was not significantly different in the groups post-test. At day 7 , the anxiety levels for placebo and CBD group did not differ. CBD did not increase depression (in contrast to the selective CB1 antagonist rimonabant). CBD might weaken the attentional bias to smoking cues or could have disrupted reconsolidation, thereby destabilizing drug-related memories. ${ }^{59}$

\section{Cell migration}

According to our literature survey, there currently are no studies about CBD role in embryogenesis/cell migration in humans, even though cell migration does play a role in embryogenesis and $\mathrm{CBD}$ was shown to be able to at least influence migratory behavior in cancer. ${ }^{1}$

\section{Endocrine effects and glycemic (including appetite)} effects

To the best of our knowledge, no acute studies were performed that solely concentrated on CBD glycemic effects. Moreover, the only acute study that also measured $\mathrm{CBD}$ effect on appetite was the study we described above, comparing different cannabis strains. In this study, the strain high in CBD elicited less appetite increase compared to the THConly strain. ${ }^{52}$

Eleven healthy volunteers were treated with $300 \mathrm{mg}$ (seven patients) and $600 \mathrm{mg}$ (four patients) oral CBD in a double-blind, placebo-controlled study. Growth 
hormone and prolactin levels were unchanged. In contrast, the normal decrease of cortisol levels in the morning (basal measurement $=11.0 \pm 3.7 \mu \mathrm{g} / \mathrm{dl} ; 120 \mathrm{~min}$ after placebo $=7.1 \pm 3.9 \mu \mathrm{g} / \mathrm{dl}$ ) was inhibited by CBD treatment (basal measurement $=10.5 \pm 4.9 \mu \mathrm{g} / \mathrm{dl} ; 120 \mathrm{~min}$ after $300 \mathrm{mg} \quad \mathrm{CBD}=9.9 \pm 6.2 \mu \mathrm{g} / \mathrm{dl} ; 120 \mathrm{~min}$ after $600 \mathrm{mg} \mathrm{CBD}=11.6 \pm 11.6 \mu \mathrm{g} / \mathrm{dl}) .^{60}$

A more recent study also used $600 \mathrm{mg}$ oral CBD for a week and compared 24 healthy subjects to people at risk for psychosis $(n=32 ; 16$ received placebo and 16 CBD). Serum cortisol levels were taken before the TSST (Trier Social Stress Test), immediately after, as well as 10 and $20 \mathrm{~min}$ after the test. Compared to the healthy individuals, the cortisol levels increased less after TSST in the 32 at-risk individuals. The CBD group showed less reduced cortisol levels but differences were not significant. ${ }^{61}$ It has to be mentioned that these data were presented at a conference and are not yet published (to our knowledge) in a peerreviewed journal.

\section{Chronic CBD Studies in Humans}

Truly chronic studies with CBD are still scarce. One can often argue that what the studies call "chronic" CBD administration only differs to acute treatment, because of repeated administration of CBD. Nonetheless, we also included these studies with repeated CBD treatment, because we think that compared to a one-time dose of $\mathrm{CBD}$, repeated $\mathrm{CBD}$ regimens add value and knowledge to the field and therefore should be mentioned here.

\section{CBD-drug interactions}

An 8-week-long clinical study, including 13 children who were treated for epilepsy with clobazam (initial average dose of $1 \mathrm{mg} / \mathrm{kg}$ b.w.) and CBD (oral; starting dose of $5 \mathrm{mg} / \mathrm{kg}$ b.w. raised to maximum of $25 \mathrm{mg} / \mathrm{kg}$ b.w.), showed the following. The CBD interaction with isozymes CYP3A4 and CYP2C19 caused increased clobazam bioavailability, making it possible to reduce the dose of the antiepileptic drug, which in turn reduced its side effects. ${ }^{62}$

These results are supported by another study described in the review by Grotenhermen et al. ${ }^{63}$ In this study, 33 children were treated with a daily dose of $5 \mathrm{mg} / \mathrm{kg} \mathrm{CBD}$, which was increased every week by $5 \mathrm{mg} / \mathrm{kg}$ increments, up to a maximum level of $25 \mathrm{mg} / \mathrm{kg}$. CBD was administered on average with three other drugs, including clobazam $(54.5 \%)$, valproic acid (36.4\%), levetiracetam (30.3\%), felbamate
(21.2\%), lamotrigine (18.2\%), and zonisamide (18.2\%). The coadministration led to an alteration of blood levels of several antiepileptic drugs. In the case of clobazam this led to sedation, and its levels were subsequently lowered in the course of the study.

\section{Physiological effects}

A first pilot study in healthy volunteers in 1973 by Mincis et al. administering $10 \mathrm{mg}$ oral CBD for 21 days did not find any neurological and clinical changes (EEG; EKG). ${ }^{64}$ The same holds true for psychiatry and blood and urine examinations. A similar testing battery was performed in 1980, at weekly intervals for 30 days with daily oral CBD administration of $3 \mathrm{mg} / \mathrm{kg}$ b.w., which had the same result. ${ }^{65}$

\section{Neurological and neuropsychiatric effects}

Anxiety. Clinical chronic (lasting longer than a couple of weeks) studies in humans are crucial here but were mostly still lacking at the time of writing this review. They hopefully will shed light on the inconsistencies observerd in animal studies. Chronic studies in humans may, for instance, help to test whether, for example, an anxiolytic effect always prevails after chronic CBD treatment or whether this was an artifact of using different animal models of anxiety or depression., ${ }^{2,18}$

Psychosis and bipolar disorder. In a 4-week open trial, CBD was tested on Parkinson's patients with psychotic symptoms. Oral doses of 150-400 mg/day CBD (in the last week) were administered. This led to a reduction of their psychotic symptoms. Moreover, no serious side effects or cognitive and motor symptoms were reported. ${ }^{66}$

Bergamaschi et al. describe a chronic study, where a teenager with severe side effects of traditional antipsychotics was treated with up to $1500 \mathrm{mg} /$ day of CBD for 4 weeks. No adverse effects were observed and her symptoms improved. The same positive outcome was registered in another study described by Bergamaschi et al., where three patients were treated with a starting dose of CBD of $40 \mathrm{mg}$, which was ramped up to $1280 \mathrm{mg} /$ day for 4 weeks. ${ }^{1}$ A double-blind, randomized clinical trial of CBD versus amisulpride, a potent antipsychotic in acute schizophrenia, was performed on a total of 42 subjects, who were treated for 28 days starting with $200 \mathrm{mg}$ CBD per day each. ${ }^{67}$ The dose was increased stepwise by $200 \mathrm{mg}$ per day to $4 \times 200 \mathrm{mg}$ CBD daily (total $800 \mathrm{mg}$ per day) within the first week. The respective treatment was maintained for 
three additional weeks. A reduction of each treatment to $600 \mathrm{mg}$ per day was allowed for clinical reasons, such as unwanted side effects after week 2 . This was the case for three patients in the CBD group and five patients in the amisulpride group. While both treatments were effective (no significant difference in PANSS total score), CBD showed the better side effect profile. Amisulpride, working as a dopamine D2/D3receptor antagonist, is one of the most effective treatment options for schizophrenia. CBD treatment was accompanied by a substantial increase in serum anandamide levels, which was significantly associated with clinical improvement, suggesting inhibition of anandamide deactivation via reduced FAAH activity.

In addition, the FAAH substrates palmitoylethanolamide and linoleoyl-ethanolamide (both lipid mediators) were also elevated in the $\mathrm{CBD}$ group. $\mathrm{CBD}$ showed less serum prolactin increase (predictor of galactorrhoea and sexual dysfunction), fewer extrapyramidal symptoms measured with the Extrapyramidal Symptom Scale, and less weight gain. Moreover, electrocardiograms as well as routine blood parameters were other parameters whose effects were measured but not reported in the study. CBD better safety profile might improve acute compliance and long-term treatment adherence. ${ }^{67,68}$

A press release by GW Pharmaceuticals of September 15th, 2015, described 88 patients with treatmentresistant schizophrenic psychosis, treated either with CBD (in addition to their regular medication) or placebo. Important clinical parameters improved in the CBD group and the number of mild side effects was comparable to the placebo group. ${ }^{2}$ Table 2 shows an overview of studies with CBD for the treatment of psy- chotic symptoms and its positive effect on symptomatology and the absence of side effects. ${ }^{69}$

Treatment of two patients for 24 days with 600$1200 \mathrm{mg} /$ day CBD, who were suffering from BD, did not lead to side effects. ${ }^{70}$ Apart from the study with two patients mentioned above, CBD has not been tested systematically in acute or chronic administration scenarios in humans for BD according to our own literature search. ${ }^{71}$

Epilepsy. Epileptic patients were treated for 135 days with 200-300 mg oral CBD daily and evaluated every week for changes in urine and blood. Moreover, neurological and physiological examinations were performed, which neither showed signs of CBD toxicity nor severe side effects. The study also illustrated that CBD was well tolerated. ${ }^{65}$

A review by Grotenhermen and Müller-Vahl describes several clinical studies with $\mathrm{CBD}^{2}: 23$ patients with therapy-resistant epilepsy (e.g., Dravet syndrome) were treated for 3 months with increasing doses of up to $25 \mathrm{mg} / \mathrm{kg}$ b.w. CBD in addition to their regular epilepsy medication. Apart from reducing the seizure frequency in $39 \%$ of the patients, the side effects were only mild to moderate and included reduced/increased appetite, weight gain/loss, and tiredness.

Another clinical study lasting at least 3 months with 137 children and young adults with various forms of epilepsy, who were treated with the CBD drug Epidiolex, was presented at the American Academy for Neurology in 2015. The patients were suffering from Dravet syndrome (16\%), Lennox-Gastaut syndrome (16\%), and 10 other forms of epilepsy (some among them were very rare conditions). In this study, almost

Table 2. Studies with CBD with Patients with Psychotic Symptoms (Adapted) ${ }^{69}$

\begin{tabular}{|c|c|c|c|}
\hline Assessment & Oral CBD administration & $\begin{array}{l}\text { Total number } \\
\text { of study } \\
\text { participants }\end{array}$ & Main findings \\
\hline $\begin{array}{l}\text { BPRS (brief psychiatric } \\
\quad \text { rating scale) }\end{array}$ & Up to $1500 \mathrm{mg} /$ day for 26 days & 1 & Improvement of symptomatology, no side effects \\
\hline BPRS & Up to $1280 \mathrm{mg} /$ day for 4 weeks & 3 & $\begin{array}{l}\text { Mild improvement of symptomatology of } 1 \text { patient, } \\
\text { no side effects }\end{array}$ \\
\hline $\begin{array}{c}\text { BPRS, Parkinson Psychosis } \\
\text { Questionnaire (PPQ) }\end{array}$ & Up to $600 \mathrm{mg} /$ day for 4 weeks & 6 & Improvement of symptomatology, no side effects \\
\hline $\begin{array}{l}\text { Stroop Color Word Test, } \\
\text { BPRS, PANSS (positive and } \\
\text { negative symptom scale) }\end{array}$ & Single doses of 300 or $600 \mathrm{mg}$ & 28 & $\begin{array}{l}\text { Performance after placebo and CBD } 300 \mathrm{mg} \text { compared } \\
\text { to CBD } 600 \mathrm{mg} \text {; no effects on symptomatology }\end{array}$ \\
\hline BPRS, PANSS & Up to $800 \mathrm{mg} /$ day for 4 weeks & 39 & $\begin{array}{l}\text { CBD as effective as amisulpride in terms of improvement } \\
\text { of symptomatology; CBD displayed superior side } \\
\text { effect profile }\end{array}$ \\
\hline
\end{tabular}


$50 \%$ of the patients experienced a reduction of seizure frequency. The reported side effects were $21 \%$ experienced tiredness, $17 \%$ diarrhea, and $16 \%$ reduced appetite. In a few cases, severe side effects occurred, but it is not clear, if these were caused by Epidiolex. These were status epilepticus $(n=10)$, diarrhea $(n=3)$, weight loss $(n=2)$, and liver damage in one case.

The largest CBD study conducted thus far was an open-label study with Epidiolex in 261 patients (mainly children, the average age of the participants was 11) suffering from severe epilepsy, who could not be treated sufficiently with standard medication. After 3 months of treatment, where patients received CBD together with their regular medication, a median reduction of seizure frequency of $45 \%$ was observed. Ten percent of the patients reported side effects (tiredness, diarrhea, and exhaustion). ${ }^{2}$

After extensive literature study of the available trials performed until September 2016, CBD side effects were generally mild and infrequent. The only exception seems to be a multicenter open-label study with a total of 162 patients aged 1-30 years, with treatmentresistant epilepsy. Subjects were treated for 1 year with a maximum of $25 \mathrm{mg} / \mathrm{kg}$ (in some clinics $50 \mathrm{mg} /$ $\mathrm{kg}$ ) oral CBD, in addition to their standard medication.

This led to a reduction in seizure frequency. In this study, $79 \%$ of the cohort experienced side effects. The three most common adverse effects were somnolence $(n=41[25 \%])$, decreased appetite $(n=31[19 \%])$, and diarrhea $(n=31[19 \%]){ }^{72}$ It has to be pointed out that no control group existed in this study (e.g., placebo or another drug). It is therefore difficult to put the side effect frequency into perspective. Attributing the side effects to CBD is also not straightforward in severely sick patients. Thus, it is not possible to draw reliable conclusions on the causation of the observed side effects in this study.

Parkinson's disease. In a study with a total of 21 Parkinson's patients (without comorbid psychiatric conditions or dementia) who were treated with either placebo, $75 \mathrm{mg} /$ day CBD or $300 \mathrm{mg} /$ day CBD in an exploratory double-blind trial for 6 weeks, the higher CBD dose showed significant improvement of quality of life, as measured with PDQ-39. This rating instrument comprised the following factors: mobility, activities of daily living, emotional well-being, stigma, social support, cognition, communication, and bodily discomfort. For the factor, "activities of daily living," a possible dose-dependent relationship could exist be- tween the low and high CBD group-the two CBD groups scored significantly different here. Side effects were evaluated with the UKU (Udvalg for Kliniske Undersøgelser). This assessment instrument analyzes adverse medication effects, including psychic, neurologic, autonomic, and other manifestations. Using the UKU and verbal reports, no significant side effects were recognized in any of the CBD groups. ${ }^{73}$

Huntington's disease. Fifteen neuroleptic-free patients with Huntington's disease were treated with either placebo or oral CBD ( $10 \mathrm{mg} / \mathrm{kg}$ b.w. per day) for 6 weeks in a double-blind, randomized, crossover study design. Using various safety outcome variables, clinical tests, and the cannabis side effect inventory, it was shown that there were no differences between the placebo group and the CBD group in the observed side effects. ${ }^{6}$

\section{Immune system}

Forty-eight patients were treated with $300 \mathrm{mg} / \mathrm{kg}$ oral $\mathrm{CBD}, 7$ days before and until 30 days after the transplantation of allogeneic hematopoietic cells from an unrelated donor to treat acute leukemia or myelodysplastic syndrome in combination with standard measures to avoid GVHD (graft vs. host disease; cyclosporine and short course of MTX). The occurrence of various degrees of GVHD was compared with historical data from 108 patients, who had only received the standard treatment. Patients treated with CBD did not develop acute GVHD. In the 16 months after transplantation, the incidence of GHVD was significantly reduced in the CBD group. Side effects were graded using the Common Terminology Criteria for Adverse Events (CTCAE v4.0) classification, which did not detect severe adverse effects. ${ }^{74}$

\section{Endocrine and glycemic (including appetite, weight} gain) effects

In a placebo-controlled, randomized, double-blind study with 62 subjects with noninsulin-treated type 2 diabetes, 13 patients were treated with twice-daily oral doses of $100 \mathrm{mg}$ CBD for 13 weeks. This resulted in lower resistin levels compared to baseline. The hormone resistin is associated with obesity and insulin resistance. Compared to baseline, glucose-dependent insulinotropic peptide levels were elevated after CBD treatment. This incretin hormone is produced in the proximal duodenum by $\mathrm{K}$ cells and has insulinotropic and pancreatic $b$ cell preserving effects. CBD was well 
tolerated in the patients. However, with the comparatively low CBD concentrations used in this phase-2trial, no overall improvement of glycemic control was observed. $^{40}$

When weight and appetite were measured as part of a measurement battery for side effects, results were inconclusive. For instance, the study mentioned above, where 23 children with Dravet syndrome were treated, increases as well as decreases in appetite and weight were observed as side effects. ${ }^{2}$ An open-label trial with 214 patients suffering from treatment-resistant epilepsy showed decreased appetite in 32 cases. However, in the safety analysis group, consisting of 162 subjects, 10 showed decreased weight and 12 had gained weight. ${ }^{52}$ This could be either due to the fact that CBD only has a small effect on these factors, or appetite and weight are complex endpoints influenced by multiple factors such as diet and genetic predisposition. Both these factors were not controlled for in the reviewed studies.

\section{Conclusion}

This review could substantiate and expand the findings of Bergamaschi et al. about CBD favorable safety profile. $^{1}$ Nonetheless, various areas of CBD research should be extended. First, more studies researching CBD side effects after real chronic administration need to be conducted. Many so-called chronic administration studies, cited here were only a couple of weeks long. Second, many trials were conducted with a small number of individuals only. To perform a throrough general safety evaluation, more individuals have to be recruited into future clinical trials. Third, several aspects of a toxicological evaluation of a compound such as genotoxicity studies and research evaluating CBD effect on hormones are still scarce. Especially, chronic studies on CBD effect on, for example, genotoxicity and the immune system are still missing. Last, studies that evaluate whether CBD-drug interactions occur in clinical trials have to be performed.

In conclusion, CBD safety profile is already established in a plethora of ways. However, some knowledge gaps detailed above should be closed by additional clinical trials to have a completely well-tested pharmaceutical compound.

\section{Acknowledgments}

The study was commissioned by the European Industrial Hemp Association. The authors thank Michal Carus, Executive Director of the EIHA, for making this review possible, for his encouragement, and helpful hints.

\section{Author Disclosure Statement}

EIHA paid nova-Institute for the review. F.G. is Executive Director of IACM.

\section{References}

1. Bergamaschi MM, Queiroz RH, Zuardi AW, et al. Safety and side effects of cannabidiol, a Cannabis sativa constituent. Curr Drug Saf. 2011;6: 237-249.

2. Grotenhermen F, Müller-Vahl K. Cannabis und Cannabinoide in der Medizin: Fakten und Ausblick. Suchttherapie. 2016;17:71-76.

3. Hampson AJ, Grimaldi M, Axelrod J, et al. Cannabidiol and $\Delta 9$ tetrahydrocannabinol are neuroprotective antioxidants. PNAS. 1998;95:8268-8273.

4. Oláh A, Tóth BI, Borbíró I, et al. Cannabidiol exerts sebostatic and antiinflammatory effects on human sebocytes. J Clin Invest. 2014:124:3713.

5. Deiana S, Watanabe A, Yamasaki Y, et al. Plasma and brain pharmacokinetic profile of Cannabidiol (CBD), cannabidivarine (CBDV), Delta (9)tetrahydrocannabivarin $(\triangle 9-\mathrm{THCV})$ and cannabigerol $(C B G)$ in rats and mice following oral and intraperitoneal administration and $C B D$ action on obsessive compulsive behaviour. Psychopharmacology. 2012;219: 859-873.

6. Consroe P, Laguna J, Allender J, et al. Controlled clinical trial of cannabidiol in Huntington's disease. Pharmacol Biochem Beh. 1991;40: 701-708.

7. Bih $\mathrm{Cl}$, Chen T, Nunn AV, et al. Molecular targets of cannabidiol in neurological disorders. Neurotherapeutics. 2015;12:699-730.

8. Stout SM, Cimino NM. Exogenous cannabinoids as substrates, inhibitors, and inducers of human drug metabolizing enzymes: a systematic review. Drug Metab Rev. 2014;46:86-95.

9. Fusar-Poli P, Crippa JA, Bhattacharyya S, et al. Distinct effects of D9tetrahydro-cannabinoland cannabidiol on neural activation during emotional processing. Arch Gen Psychiat. 2009;66:95.

10. Manini AF, Yiannoulos G, Bergamaschi MM, et al. Safety and pharmacokinetics of oral cannabidiol when administered concomitantly with intravenous fentanyl in humans. J Addict Med. 2014;9: 204-210.

11. Monographie NN. Cannabidiol. Deutscher Arzneimittel-Codex (DAC) inkl. Neues Rezeptur-Formularium (NRF). DAC/NRF October 22, 2015.

12. Pelkonen $O$, Mäeenpäeä J, Taavitsainen $P$, et al. Inhibition and induction of human cytochrome P450 (CYP) enzymes. Xenobiotica. 1998;28: 1203-1253.

13. Karlgren $M$, Bergström CA. How physicochemical properties of drugs affect their metabolism and clearance. In: New horizons in predictive drug metabolism and pharmacokinetics. Royal Society of Chemistry: Cambridge, UK, 2015.

14. Ujváry I, Hanuš L. Human metabolites of cannabidiol: a review on their formation, biological activity, and relevance in therapy. Cannabis Cannabinoid Res. 2016;1:90-101.

15. Bornheim LM, Everhart ET, Li J, et al. Induction and genetic regulation of mouse hepatic cytochrome P450 by cannabidiol. Biochem Pharmacol. 1994;48:161-171.

16. Brzozowska N, Li KM, Wang XS, et al. ABC transporters P-gp and Bcrp do not limit the brain uptake of the novel antipsychotic and anticonvulsant drug cannabidiol in mice. Peer J. 2016;4:e2081.

17. Feinshtein V, Erez O, Ben-Zvi Z, et al. Cannabidiol enhances xenobiotic permeability through the human placental barrier by direct inhibition of breast cancer resistance protein: an ex vivo study. Am J Obstet Gynecol. 2013;209:573-e1.

18. Linge $R$, Jiménez-Sánchez $L, C a m p a ~ L$, et al. Cannabidiol induces rapidacting antidepressant-like effects and enhances cortical 5-HT/glutamate neurotransmission: role of 5-HT 1 A receptors. Neuropharmacology. 2016:103:16-26.

19. Schiavon AP, Bonato JM, Milani $\mathrm{H}$, et al. Influence of single and repeated cannabidiol administration on emotional behavior and markers of cell proliferation and neurogenesis in non-stressed mice. Prog Neuropsychopharmacol. 2016:64:27-34.

20. Peres FF, Levin R, Almeida V, et al. Cannabidiol, among other cannabinoid drugs, modulates prepulse inhibition of startle in the SHR animal model: 
implications for schizophrenia pharmacotherapy. Front Pharmacol. 2016;7:303.

21. Gomes FV, Issy AC, Ferreira FR, et al. Cannabidiol attenuates sensorimotor gating disruption and molecular changes induced by chronic antagonism of NMDA receptors in mice. J Neuropsychopharmacol. 2015;18:pyu041.

22. Valvassori SS, Elias G, de Souza B, et al. Effects of cannabidiol on amphetamine-induced oxidative stress generation in an animal model of mania. J Psychopharmacol. 2011;25:274-280.

23. Ren Y, Whittard J, Higuera-Matas A, et al. Cannabidiol, a nonpsychotropic component of cannabis, inhibits cue-induced heroin seeking and normalizes discrete mesolimbic neuronal disturbances. J Neurosci. 2009:29:14764-14769.

24. Sun S, Hu F, Wu J, Zhang S. Cannabidiol attenuates OGD/R-induced damage by enhancing mitochondrial bioenergetics and modulating glucose metabolism via pentose-phosphate pathway in hippocampal neurons. Redox Biol. 2017;11:577-585.

25. Schurr A, Livne A. Differential inhibition of mitochondrial monoamine oxidase from brain by hashish components. Biochem Pharmacol. 1976;25:1201-1203.

26. Alvarez FJ, Lafuente $H$, Rey-Santano MC. Neuroprotective effects of the nonpsychoactive cannabinoid cannabidiol in hypoxicischemic newborn piglets. Pediatr Res. 2008;64:653-658.

27. Valvassori SS, Bavaresco DV, Scaini G. Acute and chronic administration of cannabidiol increases mitochondrial complex and creatine kinase activity in the rat brain. Rev Bras Psiquiatr. 2013;35: 380-386.

28. Scott KA, Dennis, JL, Dalgleish AG, et al. Inhibiting heat shock proteins can potentiate the cytotoxic effect of cannabidiol in human glioma cells. Anticancer Res. 2015;35:5827-5837.

29. Burstein S. Cannabidiol (CBD) and its analogs: a review of their effects on inflammation. Bioorg Med Chem. 2015;23:1377-1385.

30. McAllister SD, Soroceanu L, Desprez PY. The antitumor activity of plantderived non-psychoactive cannabinoids. J Neuroimmune Pharmacol. 2015;10:255-267.

31. Cheng D, Spiro AS, Jenner AM, et al. Long-term cannabidiol treatment prevents the development of social recognition memory deficits in Alzheimer's disease transgenic mice. J Alzheimers Dis. 2014;42:13831396.

32. Weiss $L$, Zeira $M$, Reich $S$, et al. Cannabidiol arrests onset of autoimmune diabetes in NOD mice. Neuropharmacology. 2008;54:244-249.

33. Hammell DC, Zhang LP, Ma F, et al. Transdermal cannabidiol reduces inflammation and pain-related behaviours in a rat model of arthritis. Eur J Pain. 2015;20:936-948.

34. Murase R, Limbad C, Murase R. Id-1 gene and protein as novel therapeutic targets for metastatic cancer. Cancer Res. 2012;72:5308.

35. Paria, BC, Das SK, Dey SK. The preimplantation mouse embryo is a target for cannabinoid ligand-receptor signaling. PNAS. 1995;92: 9460-9464.

36. Leanza L, Managò A, Zoratti M, et al. Pharmacological targeting of ion channels for cancer therapy: in vivo evidences. Biochim Biophys Acta. 2016;1863:1385-1397.

37. Ramer R, Merkord J, Rohde H, et al. Cannabidiol inhibits cancer cell invasion via upregulation of tissue inhibitor of matrix metalloproteinases-1. Biochem Pharmacol. 2010;79:955-966.

38. Ramer R, Bublitz K, Freimuth N. Cannabidiol inhibits lung cancer cell invasion and metastasis via intercellular adhesion molecule-1. FASEB J. 2012;26:1535-1548.

39. Benhamou Y. Gene and protein as novel therapeutic targets for metastatic cancer. Available at www.marschallplan.at (accessed on October 1, 2016).

40. McAllister SD, Christian RT, Horowitz MP. Cannabidiol as a novel inhibitor of Id-1 gene expression in aggressive breast cancer cells. Mol Cancer Ther. 2007;6:2921-2927.

41. De Petrocellis L, Ligresti A, Schiano Moriello A, et al. Non- $\Delta 9-\mathrm{THC}$ cannabinoids inhibit prostate carcinoma growth in vitro and in vivo: proapoptotic effects and underlying mechanisms. Br J Pharmacol. 2013;168:79-102.

42. Fowler CJ. Delta9-tetrahydrocannabinol and cannabidiol as potential curative agents for cancer: a critical examination of the preclinical literature. Pharmacol Ther. 2015;97:587-596.
43. Aviello G, Romano B, Borrelli F, et al. Chemopreventive effect of the nonpsychotropic phytocannabinoid cannabidiol on experimental colon cancer. J Mol Med. 2012;90:925-934.

44. Jadoon KA, Ratcliffe SH, Barrett DA. Efficacy and safety of cannabidiol and tetrahydrocannabivarin on glycemic and lipid parameters in patients with type 2 diabetes: a randomized, double-blind, placebo-controlled, parallel group pilot study. Diabetes Care. 2016;39:1777-1786.

45. Watanabe K, Motoya E, Matsuzawa N, et al. Marijuana extracts possess the effects like the endocrine disrupting chemicals. Toxicology. 2005;206:471-478.

46. Narimatsu S, Watanabe K, Yamamoto I. Inhibition of hepatic microsomal cytochrome P450 by cannabidiol in adult male rats. Chem Pharm Bull. 1990;38:1365-1368.

47. Jones NA, Hill AJ, Smith I, et al. Cannabidiol displays antiepileptiform and antiseizure properties in vitro and in vivo. J Pharm Ex Ther. 2010;332:569577.

48. Jones NA, Glyn SE, Akiyama S, et al. Cannabidiol exerts anti-convulsant effects in animal models of temporal lobe and partial seizures. Seizure. 2012;21:344-352.

49. Fasinu PS, Phillips S, ElSohly MA, et al. Current status and prospects for cannabidiol preparations as new therapeutic agents. Pharmacotherapy. 2016;36:781-796.

50. Persson A, Ingelman-Sundberg M. Pharmacogenomics of cytochrome P450 dependent metabolism of endogenous compounds: implications for behavior, psychopathology and treatment. J Pharmacogenomics Pharmacoproteomics 2014;5:127.

51. Ghosh C, Hossain M, Solanki J, et al. Pathophysiological implications of neurovascular P450 in brain disorders. Drug Discov Today. 2016;21:16091619.

52. Brunt TM, van Genugten M, Höner-Snoeken K, et al. Therapeutic satisfaction and subjective effects of different strains of pharmaceutical-grade cannabis. J Clin Psychopharmacol. 2014;34:344-349.

53. Das RK, Kamboj SK, Ramadas M, et al. Cannabidiol enhances consolidation of explicit fear extinction in humans. Psychopharmacology. 2013;226:781-792.

54. Bhattacharyya S, Morrison PD, Fusar-Poli P, et al. Opposite effects of $\Delta$-9-tetrahydrocannabinol and cannabidiol on human brain function and psychopathology. Neuropsychopharmacology. 2010;35:764-774.

55. Martin-Santos R, Crippa J, Batalla A. Acute effects of a single, oral dose of d9-tetrahydrocannabinol $(\triangle 9-T H C)$ and cannabidiol (CBD) administration in healthy volunteers. Curr Pharm Des. 2012;18:4966-4979.

56. Crippa JAS, Hallak JEC, Machado-de-Sousa JP, et al. Cannabidiol for the treatment of cannabis withdrawal syndrome: a case report. J Clin Pharm Ther. 2013;38:162-164.

57. Morgan CJ, Freeman TP, Schafer GL. Cannabidiol attenuates the appetitive effects of $\Delta 9$-tetrahydrocannabinol in humans smoking their chosen cannabis. Neuropsychopharmacology. 2010;35:1879-1885.

58. Hurd YL, Yoon M, Manini AF. Early phase in the development of cannabidiol as a treatment for addiction: opioid relapse takes initial center stage. Neurotherapeutics. 2015;12:807-815.

59. Morgan CJ, Das RK, Joye A, et al. Cannabidiol reduces cigarette consumption in tobacco smokers: preliminary findings. Addictive Behav. 2013;38:2433-2436.

60. Zuardi AW, Guimaraes FS, Moreira AC. Effect of cannabidiol on plasma prolactin, growth hormone and cortisol in human volunteers. Braz J Med Biol Res. 1993;26:213-217.

61. Appiah-Kusi E, Mondelli V, McGuire P, et al. Effects of cannabidiol treatment on cortisol response to social stress in subjects at high risk of developing psychosis. Psychoneuroendocrinology. 2016; 7(Supplement):23-24.

62. Geffrey AL, Pollack SF, Bruno PL, et al. Drug-drug interaction between clobazam and cannabidiol in children with refractory epilepsy. Epilepsia. 2015;56:1246-1251.

63. Grotenhermen F, Gebhardt K, Berger M. Cannabidiol. Nachtschatten Verlag: Solothurn, Switzerland, 2016.

64. Mincis M, Pfeferman A, Guimarães RX. Chronic administration of cannabidiol in man. Pilot study. AMB Rev Assoc Med Bras. 1973;19: 185-190.

65. Cunha J, Carlini EA, Pereira AE, et al. Chronic administration of cannabidiol to healthy volunteers and epileptic patients. Pharmacology. 1980;21:175185. 
66. Zuardi AW, Crippa JAS, Hallak JEC, et al. Cannabidiol for the treatment of psychosis in Parkinson's disease. J Psychopharmacol. 2009;3:979-983.

67. Leweke FM, Piomelli D, Pahlisch F. Cannabidiol enhances anandamide signaling and alleviates psychotic symptoms of schizophrenia. Transl psychiatry. 2012;2:e94.

68. Leweke F, Koethe D, Gerth C. Cannabidiol as an antipsychotic: a doubleblind, controlled clinical trial of cannabidiol versus amisulpiride in acute schizophrenia. In: 15th annual symposium on cannabinoids. Cannabinoid Research Society: Clearwater Beach, FL, 2005.

69. Iseger TA, Bossong MG. A systematic review of the antipsychotic properties of cannabidiol in humans. Schizophr Res. 2015;162:153-161.

70. Zuardi AW, Crippa JAS, Dursun SM, et al. Cannabidiol was ineffective for manic episode of bipolar affective disorder. J Psychopharmacol. 2010;24:135-137.

71. Braga RJ, Abdelmessih S, Tseng J, et al. Cannabinoids and bipolar disorder. Cannabinoids in neurologic and mental disease. Elsevier, Amsterdam, 2015, p. 205.

72. Devinsky O, Marsh E, Friedman D, et al. Cannabidiol in patients with treatment-resistant epilepsy: an open-label interventional trial. Lancet Neurol. 2016;15:270-278.

73. Chagas MHN, Zuardi AW, Tumas V, et al. Effects of cannabidiol in the treatment of patients with Parkinson's disease: an exploratory doubleblind trial. J Psychopharmacol. 2014;28:1088-1098.

74. Yeshurun M, Shpilberg O, Herscovici C, et al. Cannabidiol for the prevention of graft-versus- host-disease after allogeneic hematopoietic cell transplantation: results of a phase II study. Biol Blood Marrow Transplant. 2015;21:1770-1775.
Cite this article: Iffland K, Grotenhermen F (2017) An update on safety and side effects of cannabidiol: a review of clinical data and relevant animal studies, Cannabis and Cannabinoid Research 2:1, 139-154, DOI: 10.1089/can.2016.0034.

$\begin{aligned} & \quad \text { Abbreviations Used } \\ & \mathrm{AD}=\text { Alzheimer's disease } \\ & \mathrm{ARCl}=\text { Addiction Research Center Inventory } \\ & \mathrm{BD}=\text { bipolar disorder } \\ & \mathrm{BDI}=\text { Beck Depression Inventory } \\ & \mathrm{CBD}=\text { cannabidiol } \\ & \mathrm{HSP}=\text { heat shock protein } \\ & \mathrm{IL}=\text { interleukin } \\ & \mathrm{MRS}=\text { Mood Rating Scale } \\ & \mathrm{PPI}=\text { prepulse inhibition } \\ & \mathrm{ROS}=\text { reactive oxygen species } \\ & \mathrm{SAFTEE}=\text { Systematic Assessment for Treatment Emergent Events } \\ & \mathrm{STAI}=\text { State Trait Anxiety Inventory } \\ & \mathrm{TSST}=\text { Trier Social Stress Test } \\ & \mathrm{UKU}=\text { Udvalg for Kliniske Unders } \varnothing \text { gelser } \\ & \text { VAMS }=\text { Visual Analogue Mood Scale } \\ & \mathrm{VAS}=\text { Visual Analog Scales }\end{aligned}$

\section{Publish in Cannabis and Cannabinoid Research}

Cannabis and Cannabinoid

Research
- Immediate, unrestricted online access

- Rigorous peer review

- Compliance with open access mandates

- Authors retain copyright

- Highly indexed

- Targeted email marketing 